\title{
KAJIAN TENTANG EFEKTIFITAS MOBIL LISTRIK DALAM MENUNJANG TRANSPORTASI KAMPUS \\ (Studi Kasus: Kampus IPB Dramaga)
}

\author{
Mahdi, Muhamad Lutfi \\ Program Studi Teknik Sipil, Universitas Ibn Khaldun Bogor \\ E-mail: mail.ikhwan95@gmail.com
}

\begin{abstract}
ABSTRAK
Kampus merupakan tempat untuk mencari ilmu yang digunakan mahasiswa untuk menempuh jenjang pendidikan yang tinggi. Pendidikan tinggi merupakan jenjang pendidikan ditempuh setelah pendidikan menengah, mencakup program pendidikan Diploma, Sarjana, Magister dan Doktor. Kampus Institut Pertanian Bogor (IPB) tahun 2020 mencanangkan Green Kampus. Green transportation merupakan Visi awal Perguruan tinggi bertaraf Internasional. Tujuan Penelitian mendapatkan efektifitas penggunaan mobil listrik terhadap pelayanan pemakai moda transportasi moli di lingkungan kampus IPB Dramaga. Mobil listrik adalah kendaraan yang di gerakkan oleh listrik Accu (DC) .yang menggunakan Enegi listrik yang disimpan dalam beterai atau tempat penyimpanan energi. Panjang lintasan untuk koridor 1 sepanjang $1,7924 \mathrm{~km}$. Koridor 2 sepanjang 0,685 km, koridor 4 sepanjang $1,1955 \mathrm{~km}$ dan koridor 5 sepanjang $1,5336 \mathrm{~km}$. Load Factor untuk semua koridor dibawah $70 \%$ yaitu paling tinggi $37 \%$ yaitu Koridor 5 Perum Dosen-Gate 2 dan paling rendah $25 \%$ Koridor $1 \mathrm{FKH}-\mathrm{GWW}$ via Asrama Putri artinya tidak memenuhi. Headway jalur Moli Koridor 1 FKH-GWW via Asrama Putri sebesar 9 menit 32 detik dan yang paling rendah headway 7 menit 32 detik dengan SPM headway 5-10 menit, memenuhi SPM. Waktu Tunggu angkutan Moli paling tinggi waktu menunggu rata-rata Koridor $1 \mathrm{GWW}-\mathrm{FKH}$ via Asrama Putri yaitu 4 menit 46 detik dengan standar pelayanan minimal $5-10$ menit dan maks $10-20$ menit lebih kecil dari SPM, artinya semua koridor telah memenuhi standar pelayanan minimal (SPM). Waktu tempuh pelayanan Moli di lingkungan IPB Dramaga Koridor 5 Gate 2-Perum Dosen lebih kecil dari pada standar pelayanan minimal (SPM) sedangkan untuk Koridor $1 \mathrm{GWW}-\mathrm{FKH}$ via Asrama Putri sudah memenuhi standar pelayanan minimal (SPM).
\end{abstract}

Kata-kata kunci: Headway; koridor 1; load factor; mobil listrik

\section{ABSTRACT}

Campus is a place to seek knowledge that is used by students to pursue a high level of education. Higher education is an education level pursued after secondary education, including Diploma, Bachelor, Masters and Doctoral education programs. The Bogor Agricultural University (IPB) campus in 2020 launched the Green Campus. Green transportation is the initial vision of an international standard university. The research objective was to get the effectiveness of the use of electric cars to service users of transportation mode in the environment of Dramaga's IPB campus. Electric cars are vehicles that are driven by Accu (DC) electricity. They use electrical energy stored in batteries or energy storage areas. The track length for corridor 1 is $1.7924 \mathrm{~km}$ long. Corridor 2 is $0.685 \mathrm{~km}$, corridor 4 is $1.1955 \mathrm{~km}$ and corridor 5 is $1.5336 \mathrm{~km}$. Load Factor for all corridors is below $70 \%$, which is at most 37\%, namely Corridor 5, Lecturer Perum-Gate 2 and lowest 25\% Corridor 1 FKH-GWW via Dormitory Princess means that it does not fulfill. Moli Headway Corridor 1 FKH-GWW via Princess Dormitory is 9 minutes 32 seconds and the lowest headway is 7 minutes 32 seconds with SPM headway 5-10 minutes, fulfilling SPM. Waiting times for Moli transport are the highest waiting time for Corridor 1 GWW-FKH via Female Dormitory, which is 4 minutes 46 seconds with a minimum service standard of 5 - 10 minutes and a maximum of 10-20 minutes smaller than SPM, meaning that all corridors have met service standards minimum (SPM). Travel time for Moli services in the IPB Dramaga Corridor 5 Gate 2-Perum Lecturers are smaller than the minimum service standard (SPM) while for Corridor 1 GWW-FKH via Female Dormitory has met the minimum service standard (SPM). Key words: Headway; corridor 1; load factor; electric car

\section{PENDAHULUAN}

Kampus Institut Pertanian Bogor (IPB) tahun 2020 mencanangkan Green Kampus. Green transportation merupakan Visi awal Perguruan tinggi bertaraf Internasional. Tujuan utama dari program green transportation yaitu mengurangi polusi udara dan polusi suara bersumber dari kendaraan bermotor dengan bahan bakar premium, pertamax maupun solar. Pengalihan moda transportasi kendaraan bermotor menjadi moda transportasi kendaraan bertenaga listrik (SK Rektor IPB, 2015). IPB dalam kurun waktu sebelum 2015 sampai sekarang selalu dilewati kendaraan berbahan bakar minyak baik 
kendaraan roda empat maupun kendaraan roda dua. Kendaraan yang berbahan bakar minyak selama ini dapat mengganggu proses belajar mengajar di lingkungan kampus. Polusi udara maupun polusi suara sehingga pencemaran udara juga dapat mengganggu lingkungan kampus (Syaiful, 2005; Syaiful, 2012; Syaiful, 2015). Langkah ini memacu IPB untuk mencanangkan moda transportasi mobil listrik sebagai pengganti kendaraan berbahan bakar minyak disekitar lingkungan kampus.

Mobil listrik merupakan kendaraan berbasis tenaga listrik atau batery yang direncanakan untuk mengganti kendaraan berbasis bahan bakar minyak (BBM). Mobil listrik merupakan alternatif yang baik untuk mengatasi polusi, pencemaran lingkungan. (http://www.bolaotomotif.com/20130604).

Green transportation IPB dibutuhkan untuk mengurangi tingkat polusi udara agar terciptanya Kampus Hijau di IPB dan menertibkan kendaraan parkir liar. IPB juga menyiapkan sarana parkir untuk kendaraan pribadi yang berada di Gedung GWW, Menwa, MIPA, Green TV dan Rektorat. Kendaraan pribadi akan dikurangi aktifitasnya di lingkungan kampus, maka pihak kampus menyediakan mobil listrik sebagai moda transportasi penunjang dari dan ke lokasi yang dituju di area kampus IPB.

\section{Tujuan Penelitian}

Tujuan Penelitian ini adalah untuk mendapatkan efektifitas penggunaan mobil listrik terhadap pelayanan pemakai moda transportasi moli di lingkungan kampus IPB Dramaga.

\section{Batasan penelitiaan}

a. Lokasi penelitian diambil dari lingkungan Kampus IPB Dramaga.

b. Objek penelitian adalah moda transportasi mobil Listrik atau MOLI yaitu Koridor 2, Koridor 4 dan Koridor 5. Adapun koridor 4 dilalui Bus dan Moli sedangkan koridor 5 moli tidak beroperasi dari jam 10-14 BBWI.

\section{Angkutan}

Angkutan adalah sarana untuk memindahkan orang atau barang dari suatu tempat ke tempat lain. Tujuannya membantu orang atau kelompok orang menjangkau berbagai tempat yang dikehendaki, atau mengirimkan barangdari tempat asalnya ke tempat tujuannya. (Rudy Hermawan K, 2001)

\section{Transportasi Mobil Listrik}

Mobil listrik adalah kendaraan yang di gerakkan oleh listrik Accu (DC) .yang menggunakan Enegi listrik yang disimpan dalam beterai atau tempat penyimpanan energi.

Jenis - jenis kendaraan yang mengkonsumsi listrik adalah:
a. Mobil listrik
b. Motor listrik
c. Bus listrik
d. Sepeda listrik

Berikut ini di sampaikan keunggulan mobil listrik adalah:

a) Seratus persen Bebas Emisi

Mobil listrik memiliki emisi gas buang karbondioksida yang jauh lebih rendah dibanding mobil berbahan bakar konvensional lain.

b) Hemat Energi

Mobil listrik jauh lebih murah dan hemat energi yaitu $48 \%$ dibangdingkan mobil berbahan bakar konvensional yang mencapai efisiensi sekitar $25 \%$ dan rata-rata mobil listrik memerlukan biaya isi ulang 1 sen per mil dibandingkan dengan mobil yang memakai bahan bakar yang membutuhkan 6 sen per mil.

c) Keamanan

Faktor jaminan keamanan mobil listrik baik karena tidak melibatkan bahan bakar minyak yang dapat sewaktu-waktu terbakar atau meledak jika menabrak sesuatu.

d) Perawatan Murah

Mobil Listrik memiliki biaya pemeliharaan jauh lebih murah karena tak mempunyai ratusan komponen dalam motornya seperti mobil kenvensional. Selain itu, mobil listrik juga bisa dicuci "jangan pernah berpikir mobil listrik sangat berbahaya jika terkena air", mobil tersebut dirancang sedemikian rupa agar bisa melibas air seperti ketika dicuci, hujan, dan lainnya.

e) Nyaman Dikemudikan

Mobil listrik sama sekali tidak menimbulkan suara bising ketika dijalankan ketimbang mobil bensin. Mobil listrik juga memiliki torsi yang cukup besar sehingga dari segi performa juga cukup mumpuni. (Laporan BLST IPB, 2016; Syaiful dan Elvira Y, 2017; Syaiful, 2017). 
Mobil Listrik di IPB

Mobil Listrik di IPB mulai diterapkan sesuai SK Rektor IPB Nomor 241/IT3/LK/2015 pada tanggal 29 September 2015 tentang Green Transportasi kampus. Dan dimulai dengan pengelolaan kendaraan transportasi kampus. IPB memiliki beberapa mobil listrik atau yang lebih dikenal dengan MOLI yang didapat dari berbagai sumber, baik itu dari sumbangan maupun sponsorship seperti dari pemerintah Provinsi Jawa Barat, bank BRI, dan bank BNI 46. Program Green Transportation sendiri saat ini mengelola 35 Mobil listrik yang beroperasi di beberapa koridor. Kapasitas Mobil ini adalah 6 tempat duduk (1 driver dan 5 penumpang).

Adapun jenis MOLI yang di operasionalkan kampus IPB Dramaga terdiri dari dua macam yaitu:

a. Mobil Listrik Kursi 6 tempat duduk

\section{Pengertian Efektifitas}

Efektifitas adalah suatu ukuran yang menyatakan seberapa jauh target (kuantitas,kualitas dan waktu) telah tercapai. Dimana makin besar presentase target yang dicapai, makin tinggi efektifitasnya (Hidayat, 1986). Menurut Kamus Besar Bahasa Indonesia Efektif berarti dapat membawa hasi; dan berhasil guna. Efektifitas adalah suatu keadaan yang mengandung pengertian mengenai terjadinya sesuatu efek yang dikehendaki (The Liang Gie, 1997).

\section{Jalur Mobil Listrik}

Penelitian ini mengacu kepada keputusan dari Rektor IPB tentang transportasi di lingkungan IPB dengan menerapkan pola Green Campus IPB tahun 2020. Dalam mendukung program tersebut diterapkanlah pelayanan dengna menggunakan mobil listrik atau dikenal dengan Moli. Dalam kajian ini yang ditinjau adalah jalur dengan Koridor 1, Koridor 2, jalur Koridor 4 dan jalur Koridor 5.

Koridor 1 : GWW-FKH Via Asrama Putri dilayani oleh Bus dan Moli, Koridor 2 : FKH-FATETA-FKH dilayani hanya oleh Moli. Koridor 4 : GWW-FKH Via Rektorat dilayani oleh Bus dan Moli (hanya sampai Rektorat). Koridor 5 : Gate 2 - Perumdos dilayani hanya oleh Moli.
Mobil Listrik yang difungsikan untuk moda transportasi di dalam kampus

b. Mobil Listrik Kursi 2 tempat duduk Mobil Listrik yang difungsikan untuk Operasional (Laporan BLST, 2016).

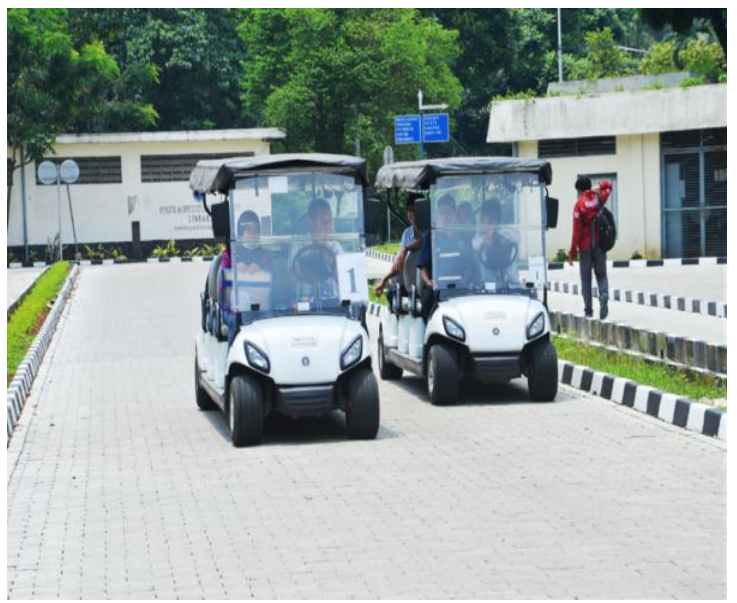

Sumber; Dokumen pribadi

Gambar 1. Mobil listrik kursi 6 tempat duduk

\section{METODE PENELITIAN Tempat dan waktu penelitian}

Tempat penelitian di Kampus IPB Dramaga Bogor, Jalan Raya Dramaga, Babakan, Dramaga, Babakan, Dramaga, Bogor, Jawa Barat 16680, Indonesia. Waktu penelitian ini dimulai bulan Pebruari dan diperkirakan selesai pada bulan Pebruari 2018. Peta lokasi ditunjukkan pada gambar 2 .

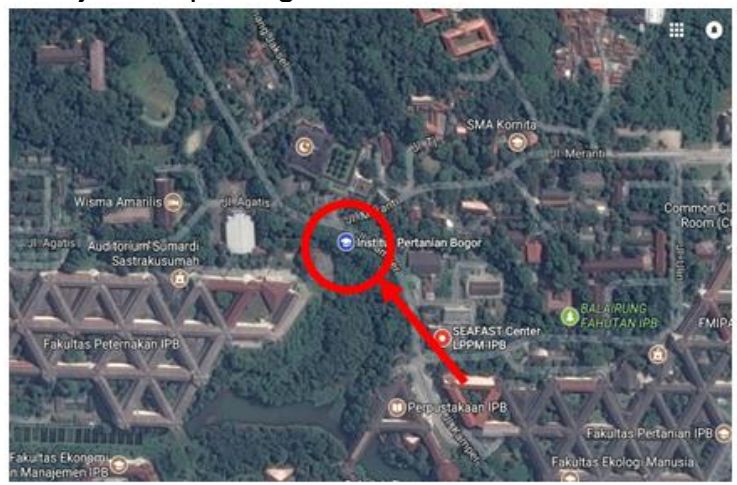

Sumber; Googlemap.2017

Gambar 2. Peta Lokasi Penelitian

\section{Tahapan Penelitian}

Penelitian ini dibagi dalam beberapa kriteria dengan menampilkan tahapan penelitian. Adapun tahapan penelitian seperti gambar 3. dibawah ini. 


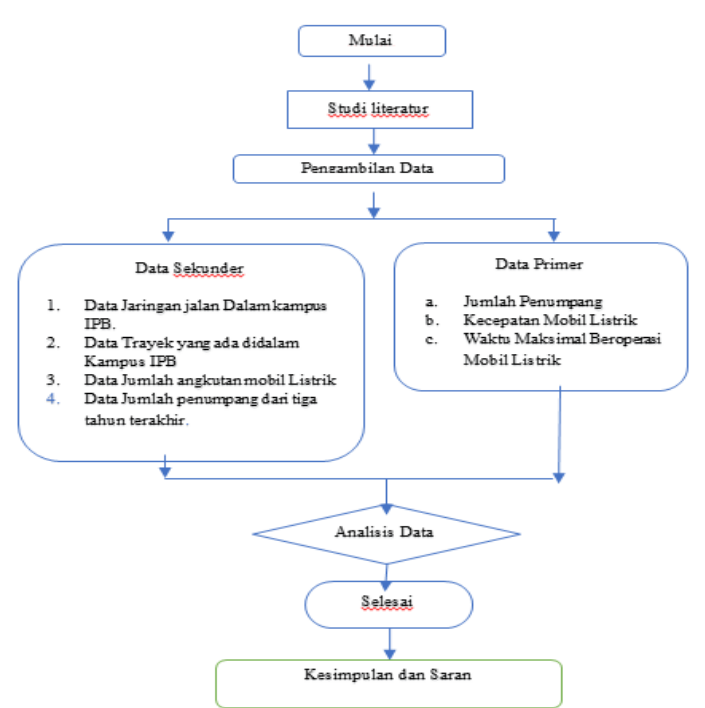

Gambar 3. Tahapan Penelitian

\section{HASIL DAN BAHASAAN \\ Hasil perhitungan}

Berdasarkan data yang penulis dapatkan dari PT. BLST/PT Bogor Life Science and Technology Holding Company of IPB sebanyak 30 Armada. Selanjutnya ditampilkan berdasarkan pada tabel 1 . di bawah ini.

Tabel 1. Jumlah armada Moli tahun 2017

\begin{tabular}{|c|c|c|c|}
\hline$N_{0}$ & Kode Lambung & Status & Kategori Kerusakan \\
\hline 1 & 2 & 3 & 4 \\
\hline 1 & $\begin{array}{c}020,026,028,024,025,030, \\
006,016,019,034,035,014, \\
012,010\end{array}$ & Beroperasi secara & Penuh \\
\hline 2 & 033 & Tusak Ringan \\
\hline 3 & $\begin{array}{c}022,005,007,021,013,027, \\
004,018,009,003,028,031, \\
011,015,008\end{array}$ & Tidak Beroperasi & Rusak Berat \\
& & & \\
\hline
\end{tabular}

Sumber : PT. BLST untuk IPB

a. Panjang Lintasan untuk tiap-tiap koridor

Panjang lintasan untuk koridor 1 sepanjang 1,7924 km. Koridor 2 sepanjang 0,685 km, koridor 4 sepanjang $1,1955 \mathrm{~km}$ dan koridor 5 sepanjang $1,5336 \mathrm{~km}$. Ada 4 koridor yang dilewati kendaraan Moli yaitu Koridor 1, 2, 4 dan koridor 5 .

Tabel 2. Halte yang dilewati serta nama halte dan jumlah kendaraan

\begin{tabular}{|c|c|c|c|}
\hline No & Kode Halte & $\begin{array}{c}\text { Nama Halte yang } \\
\text { dilewati }\end{array}$ & $\begin{array}{c}\text { Kendaraan yang } \\
\text { tersedia }\end{array}$ \\
\hline $\mathbf{1}$ & $\mathbf{2}$ & $\mathbf{3}$ & $\mathbf{4}$ \\
\hline 1 & 6 & Halte FKH & Bus dan Moli \\
\hline 2 & 7 & Halte FPIK & Bus dan Moli \\
\hline 3 & 8 & Halte GOR lama & Bus dan Moli \\
\hline 4 & 9 & Halte Al Hurnyyah & Bus dan Moli \\
\hline 5 & 10 & $\begin{array}{c}\text { Halte Asrama } \\
\text { Intemasional }\end{array}$ & Bus dan Moli \\
\hline 6 & 11 & Halte Fahutan & Bus dan Moli \\
\hline 7 & 12 & Halte Menwa & Bus dan Moli \\
\hline 8 & 13 & Halte Tanoto & Bus dan Moli \\
\hline 9 & 14 & Halte Asrama Putri & Bus dan Moli \\
\hline 10 & 15 & $\begin{array}{c}\text { Halte Student } \\
\text { Center/FMIPA/Gor } \\
\text { lama }\end{array}$ & Bus dan Moli \\
& & Halte Berlin & Bus dan Moli \\
\hline 11 & 16 & & \\
\hline
\end{tabular}

b. Perhitungan faktor muat (Load Factor)

Load factor atau kepenuh sesakan (overcrowding) adalah indikator yang menggambarkan tingkat muat angkutan. Load factor untuk koridor 1, 2, 4 dan 5 . Dan didapatkan bahwa Koridor 5 Perum Dosen - Gate 2 yang dilewati Moli memiliki Faktor Muat (Load Factor) ratarata tertinggi yaitu sebesar $44 \%$, sedangkan Koridor 1 GWW-FKH via Asrama Putri memiliki Faktor Muat (Load Factor) rata-rata terendah yaitu sebesar $26 \%$.

\section{c. Frekuensi}

Frekuensi pelayanan untuk koridor 1, 2, 4 dan 5 dapat mengunakan metode manual cound. Didapatkan bahwa pelayanan Koridor 1, Koridor 2 dan Koridoe 4 memiliki frekuensi rata-rata tertinggi sebanyak 9 moli/jam, sedangkan pelayanan dengan frekuensi rata-rata terendah adalah Koridor 5 Perum Dosen - Gate 2 yang hanya sebanyak 4 moli/jam.

d. Headway

Headway untuk untuk koridor 1, 2, 4 dan 5 didapatkan pelayanan pada Koridor 1 FKH-GWW via Asrama Putri dan GWWFKH via Asrama Putri memiliki headway tertinggi sebesar 11,67 atau $\mathbf{1 1}$ menit $\mathbf{4 0}$ detik dan terendah pada Koridor 5 Gate 2 - Perum Dosen yang hanya sebesar 6,25 atau 6 menit 15 detik.

e. Waktu Tunggu

Waktu Tunggu untuk koridor 1, 2, 4 dan 5 didapatkan pelayanan pada Koridor 1 FKH-GWW via Asrama Putri dan GWWFKH via Asrama Putri memiliki headway tertinggi sebesar 5,83 atau $\mathbf{5}$ menit $\mathbf{5 0}$ detik dan terendah pada Koridor 5 Gate 2 - Perum Dosen yang hanya sebesar 3,13 atau $\mathbf{3}$ menit $\mathbf{8}$ detik.

f. Waktu Tempuh (Round Trip Time/RTT) 
Waktu Tempuh (Round Trip Time/RTT) perjalanan untuk koridor 1, 2, 4 dan 5 didapatkan bahwa pada Koridor 4 Gate 2Perum Dosen dan Perum Dosen-Gate 2 memiliki waktu tempuh (Round Trip Time/RTT) rata-rata tertinggi sebesar 45 menit 52 detik dan terendah pada Koridor 2 FKH-FATETA dan FKH-FaTETA dengan waktu tempuh rata-rata hanya sebesar 34 menit 36 detik.

\section{Standar kinerja moli Standar Pelayanan Minimum (SPM)}

Dimana Standar Pelayanan Angkutan Umum yang penulis jadikan acuan adalah berdasarkan SK Dirjen Perhubungan Darat No: SK.687/AJ.206/DRJD/2002 dan World Bank.

a. Standar Pelayanan Mobil Listrik kampus IPB Dramaga Bogor

Ketahanan baterai moli rata-rata selama 4 jam pemakaian. Dengan jam operasional 12 jam maka dibutuhkan 3 shift moli setiap harinya yaitu shift pagi pada pukul 06.0014.00, shift middle 10.00-18.00 dan satu shift sebagai backup pada jam istirahat driver dan tambahan pada jam-jam ramai penggunaan moli. Jumlah moli yang dioperasikan ratarata tiap shift sebanyak 8 unit moli dari 14 unit yang layak beroperasi cadangan 6 unit untuk setiap shiftnya.

b. Standar Pelayanan Minimum (SPM) dengan headway Mobil Listrik

Standar pelayanan minimum dengan headway mobil listrik, headway ratarata pada koridor 1 , koridor 2 , koridor 4 dan koridor 5 diperoleh semua jalur Moli memenuhi standar pelayanan minimum angkutan umum.

c. Standar Pelayanan Minimum (SPM) Waktu Menunggu Maksimal dengan waktu Menunggu Mobil Listrik

Perbandingan waktu menunggu dengan standar pelayanan minimum dengan waktu menunggu mobil listrik, didapatkan bahwa waktu menunggu rata - rata pada delapan jalur moli dengan 4 koridor yang dilewati di kampus IPB Dramaga, secara garis besar rata - rata waktu menunggu penumpang masih sesuai dengan Standar Pelayanan Minimum.

d. Standar Pelayanan Minimum (SPM) load factor standar dengan load factor Mobil Listrik
Standar pelayanan minimum load factor standar dengan load factor mobil listrik, didapatkan bahwa load factor ketahui bahwa waktu menunggu rata - rata pada delapan jalur moli dengan 4 koridor yang dilewati di kampus IPB Dramaga, secara garis besar rata - rata waktu menunggu penumpang masih dibawah standar yaitu rata- $30 \%$ Standar Pelayanan Minimum.

e. Standar Pelayanan Minimum (SPM) waktu perjalanan dengan waktu perjalanan rata-rata mobil listrik Standar pelayanan minimum waktu perjalanan rata-rata dengan waktu perjalanan rata-rata moli mobil listrik, didapatkan bahwa waktu perjalanan dibawah waktu perjalanan yang dipersyaratkan SPM di kampus IPB Dramaga, secara garis besar dibawah standar Standar Pelayanan Minimum berarti sangat memenuhi.

f. Standar Pelayanan Minimum (SPM) kecepatan rata-rata dengan kecepatan rata-rata mobil listrik

Standar pelayanan minimum kecepatan rata-rata dengan kecepatan rata-rata moli mobil listrik, didapatkan kecepatan perjalanan rata-rata dibawah kecepatan perjalanan rata-rata yang dipersyaratkan SPM, artinya tidak memenuhi di kampus IPB Dramaga, secara garis besar dibawah standar Standar Pelayanan Minimum.

g. Jumlah Armada moli yang beroperasi

Jumlah armada yang beroprasi untuk koridor 1, 2, 4 dan 5 ditunjukkan pada tabel 3. di bawah ini.

Tabel 3. Jumlah Armada yang beroperasi

\begin{tabular}{|c|c|c|c|c|c|}
\hline \multirow{2}{*}{ No } & \multirow{2}{*}{ Koridor } & Halte yang Dilewati & \multicolumn{2}{|c|}{ Jumlah Moli } & \multirow{2}{*}{$\begin{array}{c}\text { Jumlah yang } \\
\text { beroperasi }\end{array}$} \\
\hline 1 & 1 & $\begin{array}{c}\text { GWW-FKH via } \\
\text { Asrama Putri }\end{array}$ & 8 & 5 & 4 \\
\hline 2 & 2 & FKH-FATETA & 9 & 5 & 4 \\
\hline 3 & 4 & $\begin{array}{r}\text { GWW- FKH via } \\
\text { Rektorat }\end{array}$ & 6 & 4 & 3 \\
\hline 4 & 5 & Gate 2-Perum Dosen & 8 & 4 & 3 \\
\hline
\end{tabular}

Sumber : Hasil Analisis 2018

Dari tabel 3 diatas dapat diketahui bahwa pada tahun 2018, rata-rata Jumlah Armada yang beroprasi tertinggi adalah Koridor $2 \mathrm{FKH}$ FATETA, sebesar $80 \%$ dan yang terendah adalah Koridor 4 GWW-FKH via Rektorat sebesar $15 \%$. 


\section{KESIMPULAN}

Setelah mengadakan survey penelitian analisa dan evaluasi kinerja angkutan Moli di lingkungan Kampus IPB Dramaga tahun 2018 diperoleh kesimpulan, antara lain sebagai berikut:

Hasil perhitungan kinerja pelayanan angkutan Moli dilingkungan Kampus IPB Dramaga dengan Standar Pelayanan IPB dan SPM (Standar Pelayanan Minimal)

Load Factor untuk semua koridor dibawah $70 \%$ yaitu paling tinggi $37 \%$ yaitu Koridor 5 Perum Dosen-Gate 2 dan paling rendah 25\% Koridor $1 \mathrm{FKH}-\mathrm{GWW}$ via Asrama Putri artinya tidak memenuhi.

Headway jalur Moli Koridor 1 FKH-GWW via Asrama Putri sebesar 9 menit 32 detik dan yang paling rendah headway 7 menit 32 detik dengan SPM headway 5-10 menit, memenuhi SPM.

Waktu Tunggu angkutan Moli paling tinggi waktu menunggu rata-rata Koridor 1 GWW-FKH via Asrama Putri yaitu 4 menit 46 detik dengan standar pelayanan minimal 5 10 menit dan maks $10-20$ menit lebih kecil dari SPM, artinya semua koridor telah memenuhi standar pelayanan minimal (SPM).

Waktu tempuh pelayanan Moli di lingkungan IPB Dramaga Koridor 5 Gate 2Perum Dosen lebih kecil dari pada standar pelayanan minimal (SPM) sedangkan untuk Koridor 1 GWW-FKH via Asrama Putri sudah memenuhi standar pelayanan minimal (SPM).

\section{DAFTAR PUSTAKA}

Hidayat, (1986), Teori Efektifitas Dalam Kinerja Karyawan. Gajah Mada University Press. Yogyakarta

https://kendaraan.org diakses hari senin tgl 04/12/2017 pukul 10.10 WIB.

https://rizkibeo.wordpress.com/2007/11/ 26/kinerja-angkutan-umum/ diakses tgl 4 Januari 2018 pukul 12.37 WIB

Nabilah Ulfah Dewi, 2017, Efektifitas Pelayanan Transportasi Publik (Studi Kasus BRT Mamminasata), Departemen IImu Administrasi Fakultas IImu Sosial dan IImu Politik Universitas Hasanuddin Makassar.

Poltak Situmeang, 2008, Analisa Kinerja Pelayanan Angkutan Mobil Penumpang Umum antar Kota (Studi kasus : Angkutan Umum Trayek Medan Tarurung), Departemen Teknik Sipil Fakultas Teknik Universitas Sumatera Utara Medan.
Rudy Hermawan K, (2001). Sistem Teknologi Transportasi. Penerbit ITB Bandung.

SK Dirjen No.687/AJ.206/DRJD/2002 tentang Pedoman Teknis Penyelenggaraan Angkutan Penumpang Umum di Wilayah Perkotaan Dalam Trayek Tetap dan Teratur.

SK Rektor IPB, (2015), tentang Green Transportation, Nomor 241/IT3/LK/2015 pada tanggal 29 September 2015 www.bolaotomotif.com/20130604/kelebi han-dan-kelemahan-mobil-listrik di pukul 20.25 diakses hari senin tgl 04/12/2017 pukul 10.10 WIB.

Syaiful, Syaiful, 2005, Analisis Kebisingan Arus Lalu Lintas Dan Geometri Jalan Di Kawasan Simpang Lima Kota Semarang. Masters thesis, program Pascasarjana Universitas Diponegoro. Diponegoro University, Semarang: INSTITUTIONAL REPOSITORY.

Syaiful (2012), STUDI KASUS TENTANG TINGKAT KEBISINGAN YANG DITIMBULKAN KENDARAAN BERMOTOR DI BOGOR (Kajian di Depan Rumah Sakit Azra Jalan Pajajaran Kota Bogor), ISSN 23024240, Vol 1, No 1 (2012).

http://ejournal.uika-

bogor.ac.id/index.php/ASTONJADRO/ar $\underline{\text { ticle/view/785 }}$

Syaiful (2015). Tingkat Resistensi Polusi Suara di Depan RSIA Sentosa Bogor, Jurnal Astonjadro, ISSN 2302-4240, Vol 4, No 2 (2015).

http://ejournal.uika-

bogor.ac.id/index.php/ASTONJADRO/arti cle/view/828

Syaiful, S., \& Elvira, Y. (2017). Case Study On Use Area Parking At New Market City Shopping Center Bogor. IJTI (International Journal Of Transportation And Infrastructure), 1(1), 34-40. Retrieved from http://jurnal.narotama.ac.id/index.php/ijti /article/view/330

Syaiful (2017) Engineering model of traffic and transportation safety with pattern of cooperation between sustainable region in Bogor, MATEC Web Conf. 13807008 DOI: $10.1051 /$ matecconf $/ 201713807008$ https://doi.org/10.1051/matecconf/20171 $\underline{3807008}$ 
Susilowati, dkk, 2011, Kajian Kinera Angkutan Umum dengan Metode Quality Function Development (WFD) pada Kawasan Industri Marmer di Kabupaten

Tulungagung, Jurusan Teknik Sipil, FT. Universitas Brawijaya, Malang. 